\title{
Moisture Adsorption and Thermodynamic Properties of California Grown Almonds (Varieties: Nonpareil and Monterey)
}

\author{
L. Z. TAitano AND R. P. Singh * \\ University of California, Davis, Department of Biological and Agricultural Engineering, One Shield Ave. \\ Davis, CA, 95616, USA \\ * Tel: +1-530-752-0811 \\ FAX: +1-530-752-2640 \\ RPSINGH@UCDAVIS.EDU
}

Received: 29 August 2011 ; Published online: 18 April 2012

\begin{abstract}
Moisture adsorption characteristics of California grown almonds (Nonpareil: pasteurized and unpasteurized almonds; Monterey: pasteurized, unpasteurized and blanched almonds) were obtained using the gravimetric method over a range of water activities from 0.11 to 0.98 at $7-50^{\circ} \mathrm{C}$. The weights of almonds were measured until samples reached a constant weight. The relationship between equilibrium moisture content and water activity was established using the Guggenheim-Anderson-de Boer model. The diffusion coefficient of water in almond kernels was calculated based on Ficks second law. The monolayer moisture value of almonds ranged from 0.020 to $0.035 \mathrm{~kg}$ water $/ \mathrm{kg}$ solids. The diffusion coefficient increased with temperature at a constant water activity, and decreased with water activity at a constant temperature. The thermodynamic properties (net isosteric heat, differential enthalpy and entropy) were also determined. The net isosteric heat of adsorption decreased with the increasing moisture content, and the plot of differential enthalpy versus entropy satisfied the enthalpy-entropy compensation theory. The adsorption process of almond samples was enthalpy driven over the range of studied moisture contents.
\end{abstract}

Keywords: Sorption properties; water uptake; storage; almonds 


\title{
Nomenclature
}

\author{
Latin Letters
}

$\Delta G \quad$ Free energy

$$
\begin{gathered}
\mathrm{J} \mathrm{mol}^{-1} \\
\mathrm{~J} \mathrm{~mol}^{-1} \\
\mathrm{~J} \mathrm{~mol}^{-1} \mathrm{~K}^{-1}
\end{gathered}
$$

$\Delta H \quad$ Differential enthalpy

$\Delta S \quad$ Differential entropy

$C, K \quad$ Constants in GAB model

$D_{\text {eff }} \quad$ Effective diffusion coefficient

$$
\mathrm{m}^{2} \mathrm{~h}^{-1}
$$

$E_{a} \quad$ Activation energy

$\mathrm{J} \mathrm{mol}^{-1}$

ERH Equilibrium relative humidity

$M \quad$ Equilibrium moisture content

$\mathrm{kg}$ water $/ \mathrm{kg}$ solids

$m \quad$ Monolayer moisture value

$m_{0}, C_{0}, K_{0}$

$q_{m}, h_{1}, h_{2}$

Adjusted constants for temperature

Coefficients related to heat of adsorption as the functions of temperature

$q_{s t} \quad$ Net isosteric heat

$R \quad$ Universal gas constant

$T \quad$ Absolute temperature

$8.314 \mathrm{~J} \mathrm{~mol}^{-1} \mathrm{~K}^{-1}$

BET Brunauer-Emmett-Teller

EMC Equilibrium moisture content

GAB Guggenheim-Anderson-de Boer model

$\mathrm{RH} \quad$ Relative humidity 


\section{Introduction}

Almonds are often used for snacks and as an ingredient in various food products: cereal bars, pastries, cookies, cakes and desserts. Consumer demand for almond-based products has rapidly grown in recent years. There are approximately 6,000 almond growers in California, supplying $80 \%$ of the global production and $100 \%$ of the domestic production (California Almond board, 2011). There are more than twenty five major almond varieties grown in California. The Nonpareil variety with light brown colour is the most grown commercial variety with the widest range of use. The Monterey variety is primarily used in processing and blanching; it has a longer narrow shape and more deeply wrinkled surface compared to the Nonpareil variety (California Almond board, 2012). The harvest of almonds usually starts from late August and lasts until late September (Perry \& Sibbett, 1998). Almonds with high moisture contents may spoil due to oxidative and biological reactions, reducing the shelf life of almonds; therefore, they need to be dried to prevent mould growth after harvest. During storage of dry almonds in a humid environment, water molecules transfer from the surrounding vapour phase onto the almond surface, and then diffuse into almond kernels until an equilibrium condition is reached. Moisture sorption isotherms describe the relationship between the equilibrium moisture content of food products and the surrounding relative humidity $(\mathrm{RH})$, and it provides critical information to optimize drying, storage, shipping and processing conditions. The moisture equilibrium process depends on many factors including temperature, $\mathrm{RH}$, pressure and the composition of material (García-Pérez, Cárcel, Clemente, \& Mulet, 2008). Many mathematical models such as BrunauerEmmettTeller (BET), GuggenheimAnderson-de Boer model (GAB), Oswin, and Halsey (Wani, Sogi, Shivhare, Ahmed, \& Kaur, 2006) have been fitted into the sorption isotherm data to explain the behavior of food products as the effects of water activity $\left(a_{w}\right)$, moisture content of samples, and temperature. Among all the isotherm models, the GAB model has been more widely used to fit the sorption data of major food products over a wide range of $a_{w}$ (Prothon
\& Ahrné, 2004), and it has been adopted as one of the standard equations to describe the sorption isotherms of plant-based agricultural products by the American Society of Agricultural Engineers (ASAE, 1999). The moisture sorption of nuts such as chestnuts (Vazquez, Chenlo, \& Moreira, 2001), sheanut kernels (Kapseu et al., 2006), and almond nuts (Pahlevanzadeh \& Yazdani, 2005; Taitano, Singh, Lee, \& Kong, 2011; Shands, Lam, \& Labuza, 2010), has been successfully fitted to the GAB model. Water vapor adsorption rate varies depending on the physical and chemical properties of samples, ambient temperature and RH. Many studies have been done on the rate and amount of mass transfer. The effective diffusion coefficient value $\left(D_{\text {eff }}\right)$ is an important property of food materials, which can be obtained by various methods (Lomauro, Bakshi, \& Labuza, 1985). Ficks second law of diffusion has been widely used to predict the $D_{\text {eff }}$ in unsteady state of diffusion, and the sample can be assumed as an infinite slab, cylinder or sphere to get the solution of unsteady state diffusion equation (Crank, 1975). In a previous study, the $D_{\text {eff }}$ of water in almond kernels was determined based on the Ficks diffusion equation by assuming the geometry of a parallelepiped dimensions (Ruiz-Beviá, FernándezSempere, Gómez-Siurana, \& Torregrosa-Fuerte, 1999). Thermodynamic properties of foods can be used to study the water-solid interaction, energy requirements, heat and mass transfer in biological system. Moisture sorption isotherm can be applied to calculate the thermodynamic functions including the isosteric heat of sorption, free energy, enthalpy and entropy (Kaya \& Kahyaoglu, 2007). The isosteric heat of sorption $\left(q_{s t}\right)$, or differential enthalpy $(\Delta H)$, indicates the binding strength of water adsorbed by the solid particles, and it can be used to estimate the energy requirements of a dehydration process. The Clausius-Clapeyron equation can be used to determine the isosteric heat of sorption. The differential entropy $(\Delta S)$ is calculated from the Gibbs-Helmholtz equation, and is associated with the forces of attraction or repulsion of water molecules to food material (Duarte Goneli, Corrêa, Horta de Oliveira, Gomes, \& Botelho, 2010). The free energy change $(\Delta G)$ value indicates the sorbents affinity for water, provid- 
ing a criterion to determine whether water sorption is a spontaneous process (Avramidis \& Vancouver, 1992; Goula, Karapantsios, Achilias, \& Adamopoulos, 2008). The enthalpy-entropy compensation theory is frequently used to describe different physical and chemical processes, and to investigate the water sorption phenomena of food materials (Sharma, Singh, Singh, Patel, \& Patil, 2009). Although moisture sorption of almonds has been studied by few investigators (Pahlevanzadeh \& Yazdani, 2005; Taitano et al., 2011; Shands et al., 2010), there is limited information about the moisture sorption in pasteurized, unpasteurized and blanched varieties of almonds grown in California, and used around the world by food processors. In addition, the diffusion property is temperature dependent, so it is also necessary to investigate diffusion properties of almonds at different temperatures. The objectives of this study were to assess the equilibrium moisture isotherms of almonds (pasteurized, unpasteurized, and blanched) at a wide range of temperatures. The thermodynamic properties were evaluated from the adsorption isotherm data.

\section{Experimental}

\section{$2.1 \quad$ Materials}

California grown almonds (Nonpareil: pasteurized and unpasteurized almonds, Monterey: pasteurized, unpasteurized and blanched almonds) were obtained from the Almond Board of California (Modesto, CA., U.S.A.). Table 2 shows the weight and dimension of almond samples. The initial moisture content of almond samples varied from 4.7 to $6.7 \%$. Almond samples were dried to a moisture content of $2.3-3.5 \%$ by placing them in desiccators over anhydrous calcium sulphate at $22^{\circ} \mathrm{C}$ for 15 days.

\subsection{Water sorption isotherm}

The equilibrium moisture contents (EMC) of almonds were obtained by using static gravimetric methods at $7,25,35$ and $50^{\circ} \mathrm{C}$. Approximately $20 \mathrm{~g}$ of almond kernels were placed in each plastic jar $(500 \mathrm{~mL})$ containing saturated salt solutions ( $\mathrm{LiCl}, \mathrm{CH}_{3} \mathrm{COOK}, \mathrm{MgCl}_{2}, \mathrm{~K}_{2} \mathrm{CO}_{3}$,
$\mathrm{Mg}\left(\mathrm{NO}_{3}\right)_{2}, \mathrm{NaNO}_{2}, \mathrm{NaCl}, \mathrm{KCl}$ and $\left.\mathrm{K}_{2} \mathrm{SO}_{4}\right)$ to maintain relative humidity ranging from 11 to 98\% (Greenspan, 1977). Crystalline thymol was placed into containers with $\mathrm{RH}$ over $70 \%$ to prevent mould growth (Menkov, 2000). The weights of almonds were periodically measured in duplicate until the variation of three consecutive weight measurements was less than $0.001 \mathrm{~g}$. The moisture content was measured in triplicate by drying about $2 \mathrm{~g}$ of ground almonds to a constant weight at $95-100^{\circ} \mathrm{C}$ under pressure $100 \mathrm{mmHg}$ $(13.3 \mathrm{kPa})$ for 5 hours in a vacuum oven (AOAC, 1990).

\subsection{Modelling sorption isotherms}

The GAB model was used to describe the relationship between equilibrium moisture content (EMC) and $a_{w}$ as follows (García-Pérez et al., 2008; Kapseu et al., 2006)

$$
M=\frac{m C K a_{w}}{\left(1-K a_{w}\right)\left(1-K a_{w}+C K a_{w}\right)}
$$

Where $\mathrm{M}, \mathrm{m}$, and $a_{w}$ represent the equilibrium moisture content ( $\mathrm{kg}$ water $/ \mathrm{kg}$ solids), monolayer moisture content ( $\mathrm{kg}$ water $/ \mathrm{kg}$ solids), and water activity of almonds, respectively; $C$ and $K$ are constants related to the sorption heat of the first layer and multilayer, respectively. The three parameters $(C, K$ and $m)$ in the GAB equation can be correlated with temperature by using Arrhenius type equations as follows (Taitano et al., 2011; Maroulis, Tsami, \& Marinos-kouris, 1988):

$$
\begin{gathered}
m=m_{0} e^{q_{m} / R T} \\
C=C_{0} e^{h_{1} / R T} \\
K=K_{0} e^{h_{2} / R T}
\end{gathered}
$$

Where, $m_{0}, C_{0}, K_{0}$ are the adjusted constants for temperature; $q_{m}, h_{1}$ and $h_{2}$ are the coefficients related to heat of adsorption as a function of temperature; $T$ is the absolute temperature in $\mathrm{K} ; R$ is the universal gas constant, 8.314 $\mathrm{J} /(\mathrm{mol} \cdot \mathrm{K})$. 
Moisture Adsorption and Thermodynamic Properties of Almonds $\mid 65$

Table 2: Weight and dimensions of almond samples.

\begin{tabular}{lcccc}
\hline Almond & Mass $(\mathrm{g})$ & Length $(\mathrm{mm})$ & Width $(\mathrm{mm})$ & Height $(\mathrm{mm})$ \\
\hline Nonpareil pasteurized & $1.063 \pm 0.079$ & $22.52 \pm 0.97$ & $12.42 \pm 0.26$ & $7.80 \pm 0.49$ \\
\cline { 2 - 5 } Nonpareil unpasteurized & $1.038 \pm 0.079$ & $22.26 \pm 0.91$ & $12.34 \pm 0.27$ & $7.74 \pm 0.33$ \\
\cline { 2 - 5 } Monterey pasteurized & $1.528 \pm 0.082$ & $27.98 \pm 1.19$ & $13.01 \pm 0.39$ & $8.29 \pm 0.53$ \\
\cline { 2 - 5 } Monterey unpasteurized & $1.467 \pm 0.104$ & $27.61 \pm 1.20$ & $13.01 \pm 0.20$ & $8.23 \pm 0.48$ \\
\cline { 2 - 5 } Monterey blanched & $1.255 \pm 0.117$ & $24.76 \pm 1.25$ & $12.49 \pm 0.98$ & $7.47 \pm 0.33$ \\
\hline
\end{tabular}

\subsection{Diffusion coefficient $\left(D_{e f f}\right)$ of water in almonds}

In this study, isotropic conditions were assumed, and the $D_{\text {eff }}$ was determined by using the equation of a parallelepiped as follows (Ruiz-Beviá et al., 1999):

$$
\begin{aligned}
& \frac{m-m_{e}}{m_{0}-m_{e}}=\frac{8^{3}}{\pi^{6}}\left[\sum_{n=0}^{\infty}(2 n+1)^{-2} e^{\frac{-D_{e f f}(2 n+1)^{2} \pi^{2} t}{4 a^{2}}}\right. \\
& \\
& \times \sum_{n=0}^{\infty}(2 n+1)^{-2} e^{\frac{-D_{e f f}(2 n+1)^{2} \pi^{2} t}{4 b^{2}}} \\
&\left.\times \sum_{n=0}^{\infty}(2 n+1)^{-2} e^{\frac{-D_{e f f}(2 n+1)^{2} \pi^{2} t}{4 c^{2}}}\right]
\end{aligned}
$$

Where, $a, b, c$ equal half distance of dimension (length, width, height) of almonds (meter); $\mathrm{m}$ is the moisture content (dry basis, kg water $/ \mathrm{kg}$ solids) of almond at time $\mathrm{t}$ (hour); $m_{0}$ is the initial moisture content of almond (dry basis, $\mathrm{kg}$ water $/ \mathrm{kg}$ solids); $m_{e}$ is the equilibrium moisture content of almond (dry basis, $\mathrm{kg}$ water $/ \mathrm{kg}$ solids). Activation energy $\left(E_{a}\right)$ was determined by an Arrhenius-type Eq. 6:

$$
\ln D_{e f f}=\ln D_{0}-\frac{E_{a}}{R T}
$$

Where, $D_{0}$ is a constant; $E_{a}$ is the activation energy $(\mathrm{J} / \mathrm{mol}) ; R$ is the universal gas constant, $8.314 \mathrm{~J} /(\mathrm{mol} . \mathrm{K}) ; T$ is the absolute temperature $(\mathrm{K})$.

\subsection{Thermodynamic properties of adsorption}

The net isosteric heat of adsorption $\left(q_{s t}\right)$ was determined by using the Clausius-Clapeyron equation (Rizvi, 1986).

$$
\left[\frac{\partial \ln \left(a_{w}\right)}{\partial(1 / T)}\right]_{m}=-\frac{q_{s t}}{R}
$$

Where $a_{w}$ is water activity; $q_{s t}$ is the net isosteric heat of sorption or differential enthalpy in $\mathrm{J} / \mathrm{mol} ; R$ is the universal gas constant, 8.314 $\mathrm{J} /(\mathrm{mol} \cdot \mathrm{K}) ; T$ is the absolute temperature in $\mathrm{K}$.

The change in the enthalpy of sorption $(\Delta H)$ and entropy $(\Delta S)$ were calculated by plotting $l n a_{w}$ against $1 / T$ for specific moisture contents of almonds, and then determining from the slope $-\Delta H / R$ and intercept $\Delta S / R$, respectively (Goula et al., 2008; Rizvi, 1986).

$$
-\ln a_{w}=-\frac{\Delta H}{R T}+\frac{\Delta S}{R}
$$

Where $\Delta S$ is the change in entropy, $\mathrm{J} /(\mathrm{mol} \cdot \mathrm{K})$; $\Delta H$ is the change in enthalpy, $\mathrm{J} / \mathrm{mol} ; R$ is the universal gas constant, $8.314 \mathrm{~J} /(\mathrm{mol} \cdot \mathrm{K}) ; T$ is the absolute temperature in $\mathrm{K}$. A linear relationship between enthalpy $(\Delta H)$ and entropy $(\Delta S)$ for water sorption has been reported in some starchy and sugar-rich foods, such as rice, corn, potatoes, and nuts (Taitano et al., 2011; Aguerre, Suarez, \& Viollaz, 1986; Beristain, Garcia, \& Azuara, 1996).

$$
\Delta H=T_{B} \Delta S+\Delta G_{B}
$$

Where, $T_{B}$ is the isokinetic temperature, at which all the reactions inherent to the sorption phenomenon occur at the same rate; $\Delta G_{B}$ is the free energy at the isokinetic temperature. The harmonic mean temperature, $T_{h m}$, was used to compare with the isokinetic temperature to confirm the existence of compensation. If $T_{B}>T_{h m}$, 
the process is enthalpy controlled; otherwise, the process is considered to be entropy controlled (Leffler, 1955).

$$
T_{h m}=\frac{n}{\sum_{i=1}^{n} 1 / T}
$$

Where $T_{h m}$ is the harmonic mean temperature in $\mathrm{K} ; n$ is the number of isotherms.

\subsection{Statistical analysis}

A non-linear regression analysis was used to estimate the parameters in the GAB equation based on the duplicate moisture adsorption data. The goodness of fit of the model was determined from the mean relative percentage deviation modulus $(\bar{E} \%)$, standard error of estimate (SEE), coefficients of determination $\left(R^{2}\right)$ and residual plots (Chen \& Morey, 1988; Peng, Chen, Wu, \& Jiang, 2007; Taitano et al., 2011) .

\section{Results and Discussion}

\subsection{Moisture adsorption of almonds}

The experimental results of moisture adsorption under different temperatures and water activities are presented in Fig. 1. The adsorption curves obtained were type II sigmoid shaped isotherms. At low and intermediate $a_{w}$ (0.1-0.5), the EMC increased linearly; the EMC increased exponentially at $a_{w}>0.6$. The EMC of almonds increased with $a_{w}$ at a constant temperature; on the other hand, the EMC decreased with temperature at a constant $a_{w}$. When the temperature increased, almonds became less hygroscopic since the number of active sites for water binding was reduced as an effect of temperature (Pahlevanzadeh \& Yazdani, 2005). Similar results have been reported in other studies (Taitano et al., 2011; Lahsasni, Kouhila, Mahrouz, \& Fliyou, 2003).

The GAB model was fitted into the experimental data shown in Fig. 1. The coefficients of the GAB model for Nonpareil and Monterey almonds are given in Table 3. The model shows a high goodness of fit to the experimental data
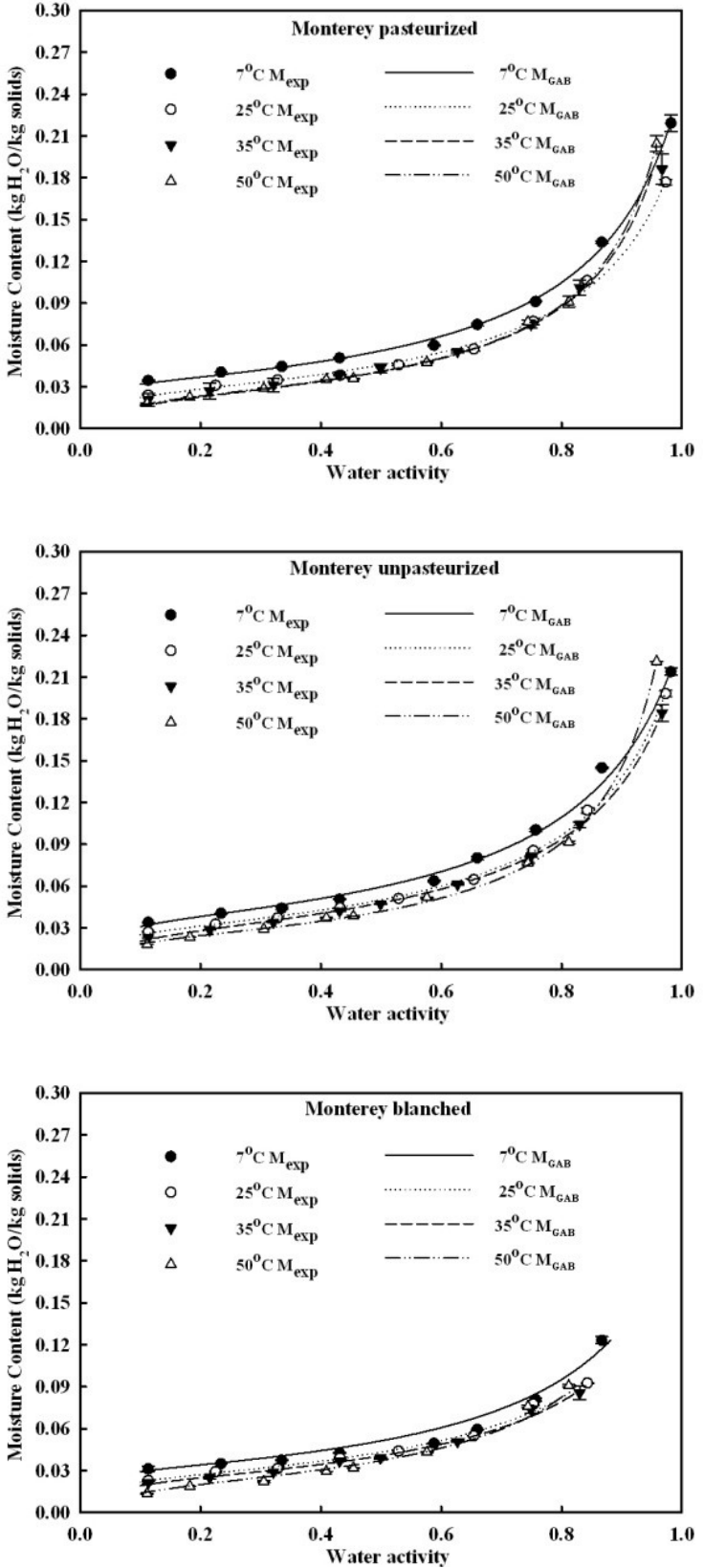

Figure 1: Experiment data of EMC of Monterey pasteurized, unpasteurized and blanched almonds at different temperature; lines correspond to the GAB model. 
with a high coefficient $R^{2}(>0.986)$ close to 1 , low $\bar{E} \%(<6.39)$ and SEE $(<0.008)$. Therefore, the GAB model adequately described the experimental moisture adsorption data of the selected almonds. The estimated monolayer moisture content $(m)$ values, corresponding to the monomolecular layer, were higher at lower temperature and within a range from 0.020 to 0.035 $\mathrm{kg}$ water $/ \mathrm{kg}$ solid. The lower monolayer moisture content $(\mathrm{m})$ values at higher temperature are due to a reduction in the total number of active sites for water molecule binding (Iglesias \& Chirife, 1976). The EMC was close to the monolayer moisture content $(\mathrm{m})$ values at $a_{w}$ around 0.32 (Fig. 1). The monolayer moisture content can be considered as the optimal moisture content for storage of almonds. The rate of any associated reaction is negligible at the monolayer moisture content because water molecules are bound with carboxyl groups or amino groups through ionic bonds, and they cannot be used as a reactant. The estimated monolayer moisture content values of Monterey and Nonpareil varieties ranged from 0.022 to $0.035 \mathrm{~kg}$ water $/ \mathrm{kg}$ solid, and 0.020 to $0.029 \mathrm{~kg}$ water $/ \mathrm{kg}$ solid, respectively. These results are comparable to the studies of five commercially processed almonds varieties stored at $a_{w} 0.05$ to 0.75 at two temperatures $\left(25\right.$ and $\left.35^{\circ} \mathrm{C}\right)$ (Shands et al., 2010).

In the GAB model, the constant $C$ indicates the sorption heat of the first layer, and the $K$ value represents the sorption heat of the multilayer. According to previous research (Blahovec, 2004), $K$ is within a range from 0 to 1 , whereas $C$ is higher than 0 . The GAB equation gives a sigmoidal shaped curve as $C$ is larger than 2; otherwise, the isotherm is of type III as $0<C<2$ (Blahovec \& Yanniotis, 2008). In Table 3 , the value of constant $C$ decreased gradually with temperature, while $K$ increased slightly. The value of $C$ is larger than 2 ; therefore, the moisture isotherm of almonds is of the type II food isotherm, as seen from moisture adsorption curves of almonds. The $K$ value of Monterey and Nonpareil almond varieties ranged from 0.85 to 0.93 (95\% confidence interval: 0.83 to 0.94 ), and from 0.88 to 0.96 (95\% confidence interval: 0.86 to 0.97 ), respectively. All the $K$ values were less than 1 , which agrees with the behaviour of other food products (Chen \& Morey, 1988; Peng et al.,
2007).

The three parameters, $m, C$, and $K$ of the GAB equation depend on temperature by Arrhenius-type equations Eqs. 2, 3, and 4, and the coefficient values are given in Table 4 . The coefficient of determination, $R^{2}$ value of Eq. 2, is within a range from 0.91 to 0.99 , indicating a goodness of fit; the $R^{2}$ value of Eq. 3 is from 0.74 to 0.99 ; the $R^{2}$ value of Eq. 4 is from 0.67 to 0.91 . The closer $R^{2}$ is to 0 , the less correlation there is between variables. Therefore, the value of $\mathrm{K}$ has less correlation with temperature, compared to the constant $\mathrm{C}$ and $\mathrm{m}$. The $95 \%$ confidence intervals were calculated (Table 4). The value of $h_{1}$ shows the difference in enthalpy between monolayer and multilayer of sorption, and the value of $h_{2}$ indicates the difference between the heat of condensation of water and the sorption heat of the multilayer. The $h_{1}$ values of almonds were positive, indicating a strong exothermic interaction of water-vapour with the primary sorption sites of food (Samaniego-Esguerra, Boag, \& Robertson, 1991; Moreira, Chenlo, Torres, \& Vallejo, 2008). For the unpasteurized almonds, the $h_{1}$ values were smaller than those of the pasteurized and blanched almonds, indicating the unpasteurized almonds have stronger exothermic interaction of water vapour with primary adsorption sites. The $h_{2}$ values were all negative and within a range from -1.47 to -0.84 , which indicate that the heat of sorption of the multilayer was greater than the heat of condensation of water. The $h_{2}$ value is in a similar range with the published values for green beans $(-0.45$ $\mathrm{kJ} / \mathrm{mol}$ ) (Samaniego-Esguerra et al., 1991). Unpasteurized almonds of different varieties have the same value of $h_{2}(-1.47 \mathrm{~kJ} / \mathrm{mol})$, which is larger than that of pasteurized and blanched almonds, demonstrating the effect of heating due to pasteurization and blanching on water binding properties.

\subsection{Diffusion of water in almonds}

The water adsorption curves of Monterey unpasteurized almonds are shown in Fig. 2. The solid lines do not represent any model, and they are presented to help the reader to follow the tendencies of moisture adsorption of almonds under dif- 
$68 \mid$ Taitano and Singh

Table 3: Estimated parameters and fitting criteria of the GAB models applied to the experimental sorption data of almonds.

\begin{tabular}{|c|c|c|c|c|c|c|c|c|}
\hline GAB model & Temp $\left({ }^{\circ} \mathrm{C}\right)$ & $a_{w}$ range & $\mathrm{C}$ & $\mathrm{K}$ & $\begin{array}{c}\text { m ( kg water } \\
\text { / kg solids) }\end{array}$ & $R^{2}$ & $\bar{E}(\%)$ & SEE \\
\hline \multirow{4}{*}{$\begin{array}{l}\text { Nonpareil } \\
\text { pasteurized }\end{array}$} & 7 & 0.110 .98 & 110.00 & 0.91 & 0.028 & 0.998 & 4.28 & 0.003 \\
\hline & 25 & 0.110 .97 & 95.98 & 0.93 & 0.024 & 0.999 & 3.30 & 0.003 \\
\hline & 35 & 0.110 .97 & 24.13 & 0.92 & 0.024 & 0.999 & 2.21 & 0.002 \\
\hline & 50 & 0.110 .96 & 10.35 & 0.96 & 0.020 & 0.999 & 2.61 & 0.003 \\
\hline \multirow{4}{*}{$\begin{array}{l}\text { Nonpareil } \\
\text { unpasteurized }\end{array}$} & 7 & 0.110 .98 & 60.00 & 0.88 & 0.029 & 0.996 & 4.39 & 0.004 \\
\hline & 25 & 0.110 .97 & 34.95 & 0.91 & 0.027 & 0.986 & 6.39 & 0.008 \\
\hline & 35 & 0.110 .97 & 25.87 & 0.90 & 0.024 & 0.992 & 4.41 & 0.005 \\
\hline & 50 & 0.110 .96 & 22.71 & 0.96 & 0.021 & 0.999 & 2.29 & 0.002 \\
\hline \multirow{4}{*}{$\begin{array}{l}\text { Monterey } \\
\text { pasteurized }\end{array}$} & 7 & 0.110 .98 & 105.00 & 0.87 & 0.032 & 0.998 & 3.13 & 0.003 \\
\hline & 25 & 0.110 .97 & 32.87 & 0.87 & 0.027 & 0.996 & 3.79 & 0.003 \\
\hline & 35 & 0.110 .97 & 15.18 & 0.92 & 0.024 & 1.000 & 2.24 & 0.001 \\
\hline & 50 & 0.110 .96 & 18.52 & 0.93 & 0.024 & 0.998 & 2.15 & 0.003 \\
\hline \multirow{4}{*}{$\begin{array}{l}\text { Monterey } \\
\text { unpasteurized }\end{array}$} & 7 & 0.110 .98 & 45.02 & 0.85 & 0.035 & 0.994 & 4.18 & 0.005 \\
\hline & 25 & 0.110 .97 & 36.82 & 0.88 & 0.029 & 0.999 & 2.25 & 0.002 \\
\hline & 35 & 0.110 .97 & 19.23 & 0.87 & 0.029 & 0.999 & 2.07 & 0.002 \\
\hline & 50 & 0.110 .96 & 25.14 & 0.93 & 0.023 & 0.999 & 2.73 & 0.002 \\
\hline \multirow{4}{*}{$\begin{array}{l}\text { Monterey } \\
\text { blanched }\end{array}$} & 7 & 0.110 .98 & 105.06 & 0.86 & 0.030 & 0.995 & 4.18 & 0.004 \\
\hline & 25 & 0.110 .97 & 40.18 & 0.88 & 0.025 & 0.990 & 3.45 & 0.003 \\
\hline & 35 & 0.110 .97 & 29.58 & 0.88 & 0.024 & 0.986 & 3.89 & 0.003 \\
\hline & 50 & 0.110 .96 & 13.72 & 0.93 & 0.022 & 0.997 & 6.29 & 0.003 \\
\hline
\end{tabular}

ferent storage conditions. It took a shorter time to reach the equilibrium condition as the temperature increased. When the increasing moisture content reached a plateau stage, samples reached equilibrium. However, samples did not reach an equilibrium condition within the storage period when the water activity level was above 0.97 due to the growth of mould. The rate of moisture adsorption was more rapid in the initial stage and became slow as sample approached an equilibrium condition. The initial high rate of moisture adsorption is attributed to the capillaries on the surface of the almonds (Hsu, Kim, \& Wilson, 1983). The free capillaries gradually fill with water during storage; as the amount of free capillaries decreases, the adsorption rate decreases. Eventually, sample reaches an equilibrium point where all the free capillaries are occupied by water molecules. Similar trends were observed in the kinetic study of water uptake in other food products (Crank, 1975; Johnson \& Brennan, 2000; Alakali, Ariahu, \& Kucha, 2009).

The effective diffusion coefficient $\left(D_{\text {eff }}\right)$ was calculated from Eq. 5 based on Ficks second law of diffusion as shown in Table 5. Under a constant temperature, $D_{\text {eff }}$ decreased with an increase in $\mathrm{RH}$; whereas $D_{\text {eff }}$ increased with temperature under a constant RH. $D_{\text {eff }}$ values of Monterey unpasteurized almonds were almost two times greater than those of Monterey pasteurized almonds at $a_{w}<0.70$ under $50^{\circ} \mathrm{C}$. Similarly, Nonpareil unpasteurized almonds had larger $D_{\text {eff }}$ values than those of Nonpareil pasteurized almonds as temperature increased up to $50^{\circ} \mathrm{C}$ and $a_{w}<0.90$. $D_{\text {eff }}$ values of blanched almonds ranged from $0.52 \cdot 10^{-8}$ to $7.05 \cdot 10^{-8} \mathrm{~m}^{2} / \mathrm{h}$ which were much lower than those of other samples. The range of $D_{\text {eff }}$ values for the blanched almonds are in good agreement with other literature values for peeled almond nuts (Ruiz-Beviá et al., 1999).

In addition, the diffusion coefficients $\left(D_{\text {eff }}\right)$ of almonds vary with temperature, and the Arrhenius relation (Eq. 6) can be used to describe the kinetic model of diffusion phenomena under different temperatures. When $\left(\ln D_{e f f}\right)$ is plot- 
Moisture Adsorption and Thermodynamic Properties of Almonds 69

Table 5: The diffusion coefficient $\left(D_{e f f}\right)$ of water in almonds at different temperatures and water activities. The \pm number represents standard deviation.

\begin{tabular}{|c|c|c|c|c|c|c|}
\hline \multirow{3}{*}{$\begin{array}{l}\text { Temp } \\
\left({ }^{o} \mathrm{C}\right)\end{array}$} & \multirow{3}{*}{$\begin{array}{l}\text { ERH } \\
(\%)\end{array}$} & \multicolumn{2}{|c|}{ Nonpareil } & \multicolumn{3}{|c|}{ Monterey } \\
\hline & & pasteurized & Unpasteurized & pasteurized & unpasteurized & blanched \\
\hline & & $D \cdot 10^{8}\left(m^{2} / h\right)$ & $D \cdot 10^{8}\left(\mathrm{~m}^{2} / \mathrm{h}\right)$ & $D \cdot 10^{8}\left(m^{2} / h\right)$ & $D \cdot 10^{8}\left(\mathrm{~m}^{2} / \mathrm{h}\right)$ & $D \cdot 10^{8}\left(m^{2} / h\right)$ \\
\hline 7 & 43.1 & $1.42 \pm 0.10$ & $1.88 \pm 0.07$ & $2.18 \pm 0.19$ & $2.02 \pm 0.32$ & $0.86 \pm 0.08$ \\
\hline 25 & 43.2 & $7.45 \pm 2.12$ & $7.04 \pm 0.24$ & $6.00 \pm 0.05$ & $5.63 \pm 0.40$ & $3.27 \pm 0.46$ \\
\hline 35 & 43.1 & $14.88 \pm 1.15$ & $11.40 \pm 0.23$ & $7.90 \pm 0.12$ & $9.48 \pm 0.31$ & $6.60 \pm 0.92$ \\
\hline 50 & 40.9 & $26.64 \pm 4.65$ & $37.22 \pm 4.29$ & $16.85 \pm 0.42$ & $32.46 \pm 6.50$ & $4.25 \pm 0.43$ \\
\hline 7 & 58.8 & $1.30 \pm 0.03$ & $1.86 \pm 0.13$ & $1.95 \pm 0.02$ & $2.01 \pm 0.13$ & $0.64 \pm 0.03$ \\
\hline 25 & 52.9 & $5.72 \pm 0.39$ & $4.65 \pm 0.14$ & $5.05 \pm 0.08$ & $5.43 \pm 0.24$ & $2.87 \pm 0.97$ \\
\hline 35 & 49.9 & $11.30 \pm 0.02$ & $9.86 \pm 0.31$ & $7.77 \pm 0.24$ & $9.61 \pm 0.10$ & $3.83 \pm 0.02$ \\
\hline 50 & 45.4 & $23.52 \pm 2.67$ & $31.12 \pm 0.76$ & $16.84 \pm 2.84$ & $38.95 \pm 6.70$ & $3.72 \pm 0.37$ \\
\hline 7 & 66.0 & $1.10 \pm 0.32$ & $1.32 \pm 0.23$ & $1.64 \pm 0.001$ & $1.89 \pm 0.14$ & $0.60 \pm 0.002$ \\
\hline 25 & 65.4 & $3.68 \pm 0.80$ & $3.00 \pm 0.79$ & $4.27 \pm 0.18$ & $5.47 \pm 0.44$ & $1.67 \pm 0.43$ \\
\hline 35 & 62.7 & $8.10 \pm 1.05$ & $5.12 \pm 2.30$ & $7.74 \pm 0.46$ & $9.52 \pm 0.09$ & $2.81 \pm 0.091$ \\
\hline 50 & 57.6 & $20.59 \pm 1.85$ & $21.32 \pm 2.73$ & $13.90 \pm 10.45$ & $30.79 \pm 1.91$ & $7.05 \pm 0.57$ \\
\hline 7 & 75.7 & $1.17 \pm 0.14$ & $1.24 \pm 0.21$ & $1.46 \pm 0.065$ & $1.77 \pm 0.14$ & $0.52 \pm 0.04$ \\
\hline 25 & 75.3 & $3.58 \pm 0.67$ & $2.53 \pm 1.12$ & $3.79 \pm 1.63$ & $4.41 \pm 0.54$ & $2.09 \pm 0.03$ \\
\hline 35 & 74.9 & $7.15 \pm 1.19$ & $5.51 \pm 0.05$ & $6.98 \pm 0.17$ & $8.29 \pm 0.29$ & $2.61 \pm 0.15$ \\
\hline 50 & 74.4 & $12.22 \pm 1.92$ & $16.38 \pm 2.33$ & $12.76 \pm 4.14$ & $16.50 \pm 0.47$ & $5.00 \pm 1.03$ \\
\hline 7 & 86.7 & $0.96 \pm 0.19$ & $1.06 \pm 0.13$ & $1.36 \pm 0.13$ & $1.53 \pm 0.10$ & $0.57 \pm 0.03$ \\
\hline 25 & 84.3 & $3.00 \pm 0.48$ & $2.21 \pm 0.56$ & $3.33 \pm 0.05$ & $3.35 \pm 0.27$ & $1.84 \pm 0.20$ \\
\hline 35 & 83.0 & $3.60 \pm 1.37$ & $5.24 \pm 0.53$ & $6.61 \pm 0.33$ & $5.93 \pm 0.75$ & $2.74 \pm 0.32$ \\
\hline 50 & 81.2 & $8.48 \pm 0.88$ & $13.31 \pm 0.50$ & $10.22 \pm 3.84$ & $14.86 \pm 0.04$ & $4.92 \pm 0.91$ \\
\hline 7 & 98.2 & $0.68 \pm 0.32$ & $0.95 \pm 0.05$ & $1.12 \pm 0.059$ & $1.30 \pm 0.03$ & $0.73 \pm 0.04$ \\
\hline 25 & 97.3 & $2.75 \pm 0.74$ & $1.91 \pm 0.07$ & $2.74 \pm 0.45$ & $2.91 \pm 0.23$ & $3.09 \pm 0.22$ \\
\hline 35 & 96.7 & $3.66 \pm 0.81$ & $3.59 \pm 0.37$ & $5.23 \pm 0.91$ & $4.07 \pm 0.36$ & $5.60 \pm 0.80$ \\
\hline 50 & 95.8 & $5.82 \pm 0.35$ & $5.16 \pm 0.18$ & $5.69 \pm 0.30$ & $7.43 \pm 0.27$ & $4.69 \pm 0.20$ \\
\hline
\end{tabular}

Table 6: The activation energy $\left(E_{a}\right)$ for water adsorption from $D_{e f f}$.

\begin{tabular}{|c|c|c|c|c|c|c|c|c|c|c|}
\hline & \multicolumn{4}{|c|}{ Nonpareil } & \multicolumn{6}{|c|}{ Monterey } \\
\hline \multirow{2}{*}{$\begin{array}{c}\text { ERH } \\
(\%)\end{array}$} & \multicolumn{2}{|c|}{ pasteurized } & \multicolumn{2}{|c|}{ unpasteurized } & \multicolumn{2}{|c|}{ pasteurized } & \multicolumn{2}{|c|}{ unpasteurized } & \multicolumn{2}{|c|}{ blanched } \\
\hline & $\begin{array}{l}E_{a} \\
(\mathrm{~kJ} / \mathrm{m}\end{array}$ & $R^{2}$ & $\begin{array}{l}E_{a} \\
(\mathrm{~kJ} / \mathrm{m}\end{array}$ & $R^{2}$ & $\begin{array}{l}E_{a} \\
(\mathrm{~kJ} / \mathrm{m}\end{array}$ & $R^{2}$ & $\begin{array}{l}E_{a} \\
(\mathrm{~kJ} / \mathrm{m}\end{array}$ & $R^{2}$ & $\begin{array}{l}E_{a} \\
(\mathrm{~kJ} / \mathrm{m}\end{array}$ & $R^{2}$ \\
\hline $40.9-43.1$ & 52.19 & 0.977 & 51.18 & 0.992 & 35.08 & 0.992 & 47.48 & 0.977 & 29.56 & 0.719 \\
\hline $45.4-58.8$ & 51.11 & 0.993 & 49.07 & 0.976 & 37.39 & 0.998 & 50.6 & 0.964 & 31.79 & 0.808 \\
\hline $57.6-66.0$ & 51.52 & 0.998 & 47.19 & 0.94 & 37.87 & 0.997 & 48 & 0.985 & 42.84 & 0.996 \\
\hline $74.4-75.7$ & 41.92 & 0.991 & 45.01 & 0.959 & 38.48 & 0.997 & 39.48 & 0.997 & 38.9 & 0.967 \\
\hline $81.2-86.7$ & 37.01 & 0.98 & 44.79 & 0.969 & 36.32 & 0.987 & 39.54 & 0.982 & 37.61 & 0.99 \\
\hline $95.8-98.2$ & 37.6 & 0.952 & 30.75 & 0.982 & 30.14 & 0.93 & 30.27 & 0.999 & 34.79 & 0.816 \\
\hline
\end{tabular}


$70 \mid$ Taitano and Singh
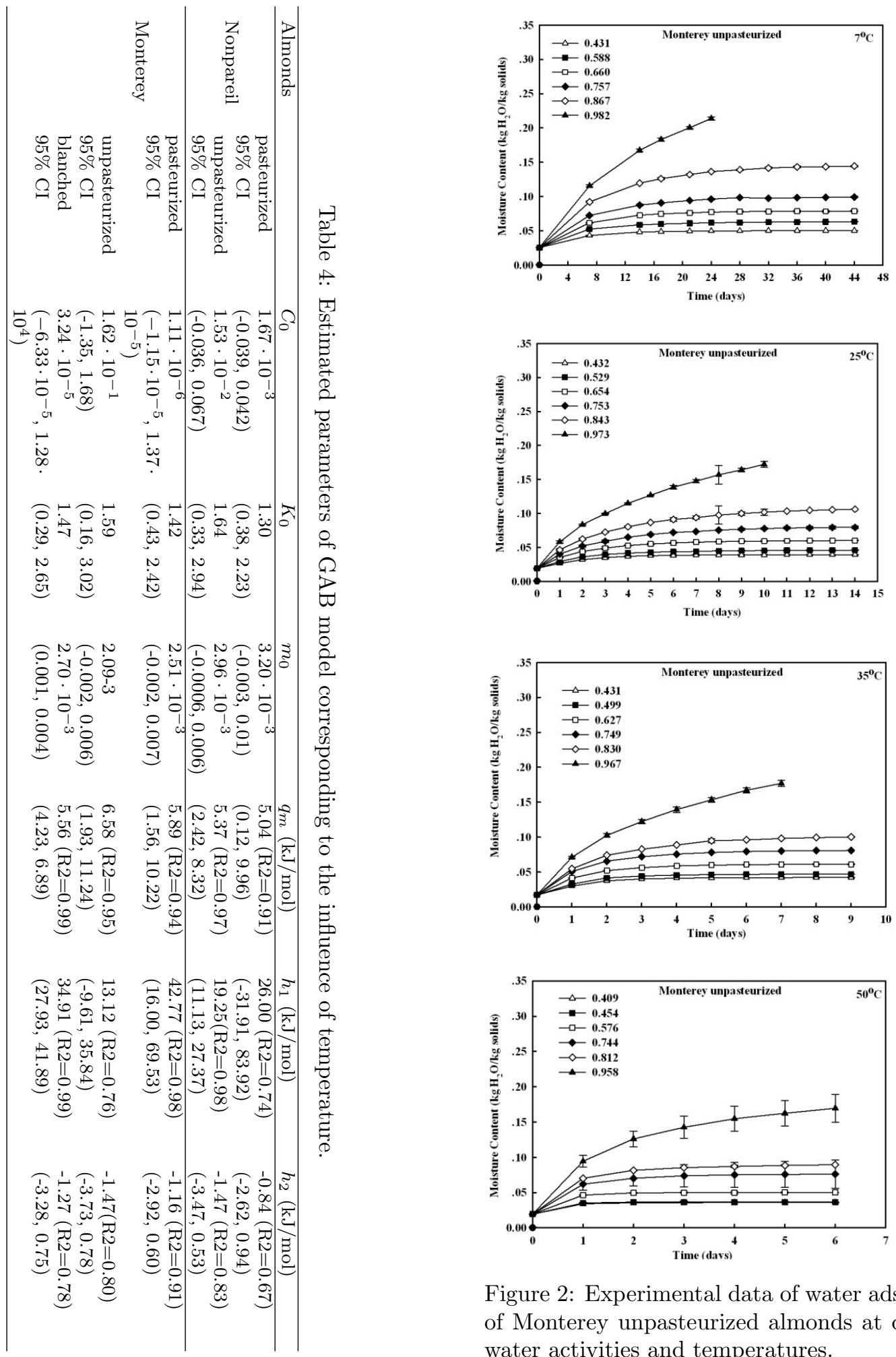

Figure 2: Experimental data of water adsorption of Monterey unpasteurized almonds at different water activities and temperatures.

IJFS | April 2012 |Volume 1 pages 61-75 
ted against the reciprocal absolute temperature, $1 / \mathrm{T}$, a straight line is obtained with a slope of $-E_{a} / R$ (Taoukis, Labuza, \& Saguy, 1996). Fig. 3 shows the Arrhenius plots of diffusion coefficient $\left(D_{\text {eff }}\right)$ for Nonpareil variety with higher $R^{2}$ ranging from 0.940 to 0.998 , which indicates that the temperature dependence of $D_{\text {eff }}$ can be properly described by the Arrhenius model. Generally, the values of activation energy $\left(E_{a}\right)$ for almonds varied with equilibrium relative humidity (ERH, \%) as presented in Table 6. The lower the diffusion rate, the lower is the $E_{a}$. At lower water activities, the attraction between water-vapour and the primary sorption sites of almonds was expected to be stronger than that at higher water activity (Samaniego-Esguerra et al., 1991). All almond samples had higher $E_{a}$ at the ERH range of $40.9-43.1 \%$ than that under higher ERH. Since the $D_{\text {eff }}$ decreases with ERH; correspondingly, the $E_{a}$ also decreases with ERH. The difference in $E_{a}$ between Nonpareil unpasteurized and pasteurized almonds is less than that of Monterey variety. As ERH increased from 40 to $98 \%$, the $E_{a}$ values of Nonpareil decreased from 52.19 to $30.75 \mathrm{~kJ} / \mathrm{mol}$. The $E_{a}$ values of Monterey unpasteurized almonds, within a range of 30.27-50.60 $\mathrm{kJ} / \mathrm{mol}$, were larger than those of pasteurized and blanched almonds within a range of 29.56$42.84 \mathrm{~kJ} / \mathrm{mol}$ except at $a_{w}>0.95$.

The difference in $D_{\text {eff }}$ values of Nonpareil pasteurized and unpasteurized almonds was less than that of Monterey pasteurized and unpasteurized; therefore, the difference in $E_{a}$ values for Nonpareil variety was less than that for Monterey variety. In this study, the size of the Nonpareil variety was smaller than that of the Monterey variety (Table 2). The $D_{\text {eff }}$ values of Nonpareil pasteurized almonds was higher than those for Monterey pasteurized almonds at $a_{w}<$ 0.75; therefore, there are larger differences in the $E_{a}$ between Nonpareil pasteurized and Monterey pasteurized almonds for $a_{w}<0.75$. The $D_{\text {eff }}$ of Monterey unpasteurized almonds was higher than that of Monterey pasteurized and blanched almonds. The $E_{a}$ of blanched almonds was lower than that of other samples at $a_{w}<0.66$. Furthermore, the variation of $D_{0}$ with $E_{a}$ followed an exponential relationship for all samples with $R^{2}$ range of $0.978-0.999$ as shown in Table 7 .
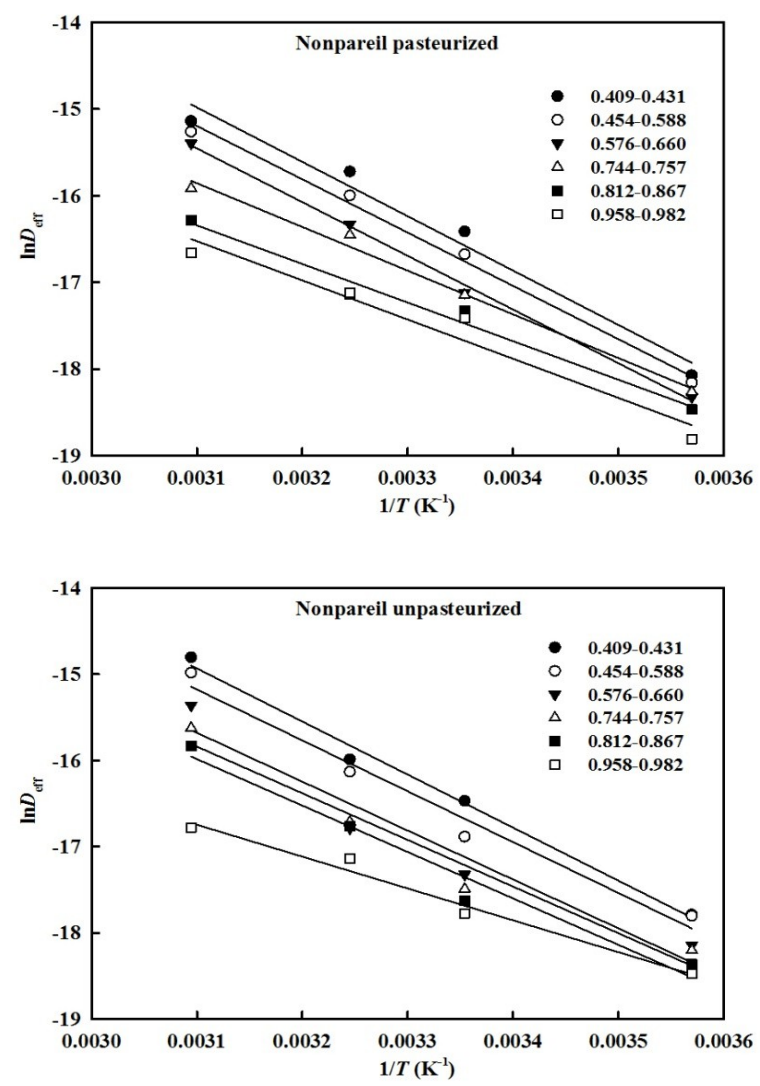

Figure 3: Arrhenius plot of $D_{e} f f$ of Nonpareil almonds

\subsection{Thermodynamic properties}

The net isosteric heat $\left(q_{s t}\right)$ of adsorption at specific moisture contents was determined from Eq. 7 by plotting $\ln \left(a_{w}\right)$ against $1 / T$, as shown in Fig. 4 . The net isosteric heat $\left(q_{s t}\right)$ of adsorption decreased as the moisture constant of almonds increased (Fig. 5). Available water binding sites reduced as the moisture content increased, resulting in lower $q_{s t}$ values (Moreira et al., 2008). The unpasteurized almonds had a lower net isosteric heat of adsorption value than those of pasteurized and blanched almonds under moisture content $<0.030 \mathrm{~kg}$ water $/ \mathrm{kg}$ solid. As moisture content increased, the $q_{s t}$ of almonds decreased and approached zero.

The thermodynamic parameters, including the differential enthalpy $(\Delta H)$, differential entropy 
Table 7: The value of $D_{0}$ and activation energy $\left(E_{a}\right)$ relationship for Nonpareil and Monterey almonds.

\begin{tabular}{lcc}
\hline Sample & Equation & Correlation coefficient \\
\hline Nonpareil pasteurized & $D_{0}=e^{0.4562 \cdot E_{a}-19.4929}$ & $R^{2}=0.997$ \\
Nonpareil unpasteurized & $D_{0}=e^{0.4561 \cdot E_{a}-19.4452}$ & $R^{2}=0.996$ \\
Monterey pasteurized & $D_{0}=e^{0.4563 \cdot E_{a}-18.9140}$ & $R^{2}=0.980$ \\
Monterey unpasteurized & $D_{0}=e^{0.4442 \cdot E_{a}-18.5912}$ & $R^{2}=0.999$ \\
Monterey blanched & $D_{0}=e^{0.3428 \cdot E_{a}-15.4847}$ & $R^{2}=0.978$ \\
\hline
\end{tabular}

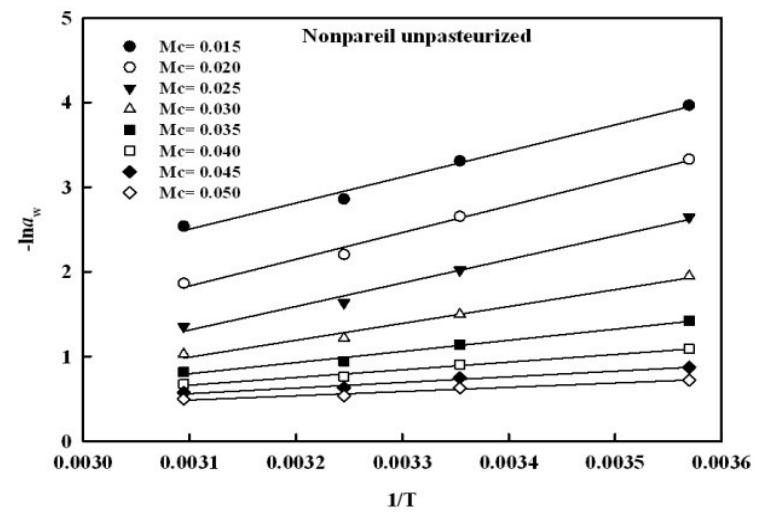

Figure 4: Plots of $\ln a_{w}$ versus $1 / T$ for calculating the net isosteric heat of sorption of Nonpareil variety almonds at constant moisture contents.

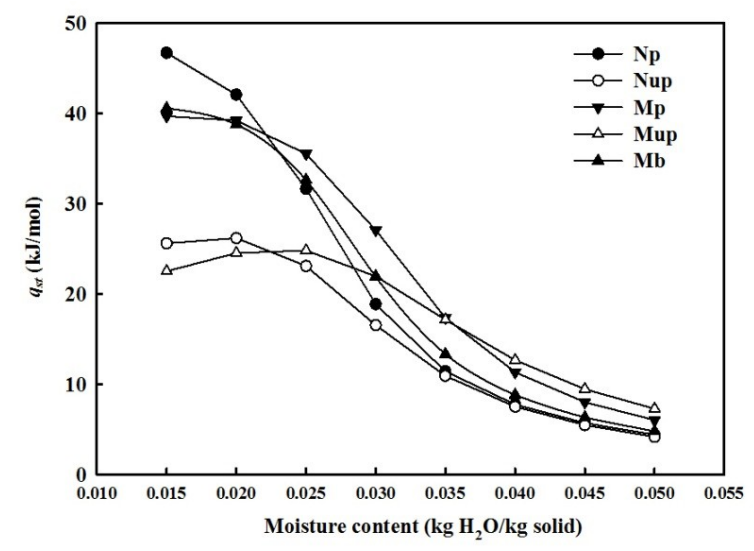

Figure 5: Net isosteric heat of adsorption values of different varieties of almonds.
$(\Delta S)$, and free energy $(\Delta G)$ of water adsorption by almonds were determined by using Eq. (8). The values of $\Delta H, \Delta S$ and $\Delta G$ decreased as the moisture contents increased. Unpasteurized almonds had a smaller $\Delta H$ value range than those of pasteurized and blanched almonds. The $\Delta S$ for unpasteurized almonds was from 8.93$64.37 \mathrm{~J} /(\mathrm{mol} \cdot \mathrm{K})$, which is less than $\Delta S$ values of pasteurized almonds 3.78-100.78 $\mathrm{J} /(\mathrm{mol} \cdot \mathrm{K})$, and blanched almonds 2.94-92.16 J/(mol-K). The difference in the adsorption enthalpy and entropy of almonds may be attributed to the effects of blanching and pasteurizing. These treatments enhance the interaction of proteins with other components such as carbohydrates and lipids. Therefore, blanched and pasteurized almonds show stronger binding forces at the active sites. However, the difference in adsorption entropy slowly decreased when moisture content was above $0.030 \mathrm{~kg} \mathrm{H}_{2} \mathrm{O} / \mathrm{kg}$ solid because the active sites on the surface of the material were occupied by the water molecules, thus decreasing the interaction forces. By plotting $\Delta H$ versus $\Delta S$, a linear relationship was found between the differential enthalpy versus entropy for almond samples with $R^{2}$ equivalent to 0.943-0.999 as shown in Fig. 6, which satisfies the theory of enthalpy-entropy compensation. According to Eq. 9, the isokinetic temperatures $\left(T_{B}\right)$ of adsorption were calculated from the slopes and ranged from 340.99 to $373.77 \mathrm{~K}$, covering the moisture contents range from 0.025 to $0.050 \mathrm{~kg}$ $\mathrm{H}_{2} \mathrm{O} / \mathrm{kg}$ solid. $T_{B}$ of unpasteurized almonds was larger than those of pasteurized and blanched almonds. The harmonic mean temperature $\left(T_{h m}\right)$ obtained from Eq. 10 was $301.585 \mathrm{~K}$, which is significantly lower than the $T_{B}$ of all almond samples. Therefore, the mechanism of the adsorption process can be characterized as enthalpy driven $\left(T_{B}>T_{h m}\right)$ in all cases. 

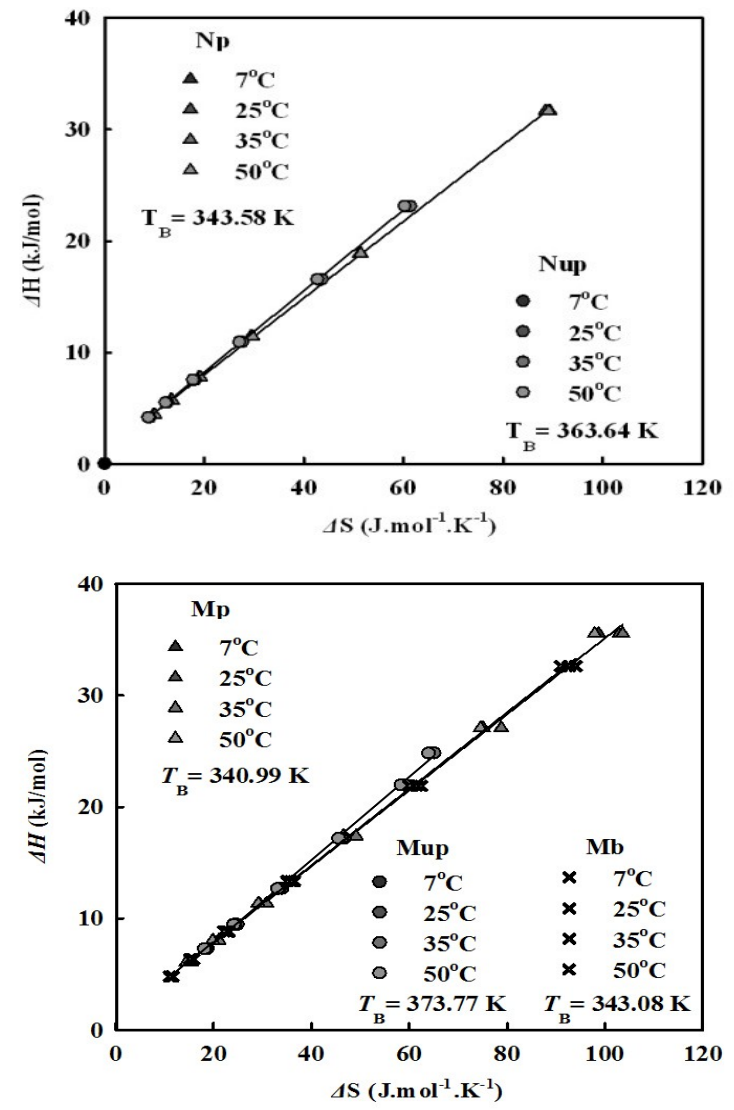

Figure 6: Heat of adsorption $(\Delta \mathrm{H}) /$ differential entropy $(\Delta S)$ relationship of different varieties of almonds. (Np: Nonpareil pasteurized; Nup: Nonpareil unpasteurized; Mp: Monterey pasteurized; Mup: Monterey unpasteurized; Mb: Monterey blanched.)

\section{Conclusion}

The EMC of almond samples increased with $a_{w}$, and $D_{\text {eff }}$ decreased with $a_{w}$ at a constant temperature; therefore, it took longer time for almonds to reach equilibrium condition at higher $a_{w}$. On the other hand, the EMC decreased with the temperature, and $D_{\text {eff }}$ increased with temperature at a constant $a_{w}$; thus high temperature accelerated almonds to reach equilibrium condition. The GAB model can appropriately fit the sorption isotherm of almonds. The estimated monolayer moisture contents of all samples ranged from 0.020 to $0.035 \mathrm{~kg} \mathrm{H}_{2} \mathrm{O} / \mathrm{kg}$ solid at the studied temperatures and $a_{w}$. The EMC can be predicted by using the GAB model under different $\mathrm{RH}$ and temperatures. Blanched almonds are less hygroscopic than the unpasteurized almonds, whereas the differences between pasteurized and unpasteurized almonds are relatively less than the difference between blanched and unpasteurized almonds. The unpasteurized almonds had a lower $q_{s t}$ of adsorption value than that of pasteurized and blanched almonds under the monolayer moisture contents. These differences can be attributed to the effects of processing on possibly modifying the degree of molecule organization. Both moisture adsorption data and $D_{\text {eff }}$ of water in almonds can provide the almond industry valuable information to control processing and storage conditions. In addition, it can also be applied to calculate moisture contents of almonds during storage, and thus predict shelflife of almonds by collaborating moisture content with other properties of almonds, to effectively control the quality of almonds.

\section{Acknowledgements}

The authors would like to thank the Almond Board of California for providing financial support and almonds for this research.

\section{References}

Aguerre, R. J., Suarez, C., \& Viollaz, P. E. (1986). Enthalpy-entropy compensation in sorption phenomena - application to the prediction of the effect of temperature on food isotherms. Journal Of Food Science, 51(6), 1547-1549. doi:10.1111/j.1365-2621. 1986.tb13856.x

Alakali, J. S., Ariahu, C. C., \& Kucha, E. I. (2009). Kinetics of moisture uptake of osmo-foam-mat dried mango powders and application of sorption isotherms to shelflife prediction. American Journal of Food Technology, 3, 119-125.

AOAC. (1990). Official methods of analysis. Association of Official Analytical Chemists: Washington, DC. 
ASAE. (1999). Moisture relationships of plantsbased agricultural products (tech. rep. No. D245.5 OCT95). ASAE.

Avramidis, S., \& Vancouver, B. C. (1992). Enthalpy-entropy compensation and thermodynamic considerations in sorption phenomena. Wood Science And Technology, 26(5), 329-333.

Beristain, C. I., Garcia, H. S., \& Azuara, E. (1996). Enthalpy-entropy compensation in food vapor adsorption. Journal of Food Engineering, 30(3-4), 405-415. doi:10 . 1016/S0260-8774(96)00011-8

Blahovec, J. (2004). Sorption isotherms in materials of biological origin mathematical and physical approach. Journal Of Food Engineering, 65(4), 489-495. doi:10.1016/j . jfoodeng.2004.02.012

Blahovec, J., \& Yanniotis, S. (2008). GAB generalized equation for sorption phenomena. Food And Bioprocess Technology, 1(1), 8290. doi:10.1007/s11947-007-0012-3

California Almond board. (2012). Almond varieties and classification. Retrieved from http : / / www . almondboard . com / FoodProfessionals / TechnicalInformation / Pages/TypesVarieties.aspx

California Almond board. (2011). An introduction to California almonds: the scope of the industry. Retrieved from http : / / www . calasfmra . com / db_meetings / Almond \% 20Board \% 20Presentation \% 20 $\%$ 20Gabriele\%20Ludwig.pdf

Chen, C., \& Morey, R. (1988). Comparison of four EMC/ERH equations. Transactions of the ASAE, 32, 983-990. Retrieved from http : / / journalseek . net / cgi - bin / journalseek/journalsearch.cgi?field=issn \& query $=0001-2351$

Crank, J. (1975). The mathematics of diffusion. Oxford University Press.

Duarte Goneli, A. L., Corrêa, P. C., Horta de Oliveira, G. H., Gomes, C. F., \& Botelho, F. M. (2010). Water sorption isotherms and thermodynamic properties of pearl millet grain. International Journal Of Food Science And Technology, 45(4), 828-838. doi:10.1111/j.1365-2621.2010.02208.x

García-Pérez, J. V., Cárcel, J. A., Clemente, G., \& Mulet, A. (2008). Water sorption isotherms for lemon peel at different temperatures and isosteric heats. LWT-food Science And Technology, 41(1), 18-25. doi:10.1016/j.lwt.2007.02.010

Goula, A. M., Karapantsios, T. D., Achilias, D. S., \& Adamopoulos, K. G. (2008). Water sorption isotherms and glass transition temperature of spray dried tomato pulp. Journal Of Food Engineering, 85(1), 7383. doi:10.1016/j.jfoodeng.2007.07.015

Greenspan, L. (1977). Humidity fixed-points of binary saturated aqueous-solutions. Journal Of Research Of The National Bureau Of Standards Section A-physics And Chemistry, 81(1), 89-96.

Hsu, K. H., Kim, C. J., \& Wilson, L. A. (1983). Factors affecting water-uptake of soybeans during soaking. Cereal Chemistry, 60(3), 208-211.

Iglesias, H. A., \& Chirife, J. (1976). Isosteric heat of water vapour sorption on dehydrated foods. Lebensmittel Wissenschaft und Technologie, 9, 116-127.

Johnson, P. N. T., \& Brennan, J. G. (2000). Kinetics of moisture absorption by plantain flour. Journal Of Food Engineering, 45(1), 33-36. doi:10.1016/S0260-8774(00)00038-8

Kapseu, C., Nkouam, G. B., Dirand, M., Barth, D., Perrin, L., \& Tchiegang, C. (2006). Water vapour sorption isotherms of sheanut kernels (Vitellaria paradoxa gaertn.). Journal of Food Technology, 4, 235-241.

Kaya, S., \& Kahyaoglu, T. (2007). Moisture sorption and thermodynamic properties of safflower petals and tarragon. Journal Of Food Engineering, 78(2), 413-421. doi:10.1016/ j.jfoodeng.2005.10.009

Lahsasni, S, Kouhila, M, Mahrouz, M, \& Fliyou, M. (2003). Moisture adsorption-desorption isotherms of prickly pear cladode (opuntia ficus indica) at different temperatures. $E n$ ergy Conversion And Management, 44(6), 923-936. doi:10 . 1016 / S0196 - 8904(02) 00094-8

Leffler, J. E. (1955). The enthalpy-entropy relationship and its implications for organic chemistry. Journal Of Organic Chemistry, 20(9), 1202-1231. doi:10 . 1021/ jo01126a009 
Moisture Adsorption and Thermodynamic Properties of Almonds $\mid 75$

Lomauro, C. J., Bakshi, A. S., \& Labuza, T. P. (1985). Moisture transfer properties of dry and semimoist foods. Journal Of Food Science, 50(2), 397-400.

Maroulis, Z. B., Tsami, E., \& Marinos-kouris, D. (1988). Application of the GAB model to the moisture sorption isotherms for dried fruits. Journal of Food Engineering, 7, 6378.

Menkov, N. D. (2000). Moisture sorption isotherms of chickpea seeds at several temperatures. Journal Of Food Engineering, 45(4), 189-194. doi:10.1016 / S02608774(00)00052-2

Moreira, R., Chenlo, F., Torres, M. D., \& Vallejo, N. (2008). Thermodynamic analysis of experimental sorption isotherms of loquat and quince fruits. Journal Of Food Engineering, 88(4), 514-521. doi:10.1016/j . jfoodeng.2008.03.011

Pahlevanzadeh, H, \& Yazdani, M. (2005). Moisture adsorption isotherms and isosteric energy for almond. Journal Of Food Process Engineering, 28(4), 331-345. doi:10.1111/ j.1745-4530.2005.00401.x

Peng, G., Chen, X. G., Wu, W. F., \& Jiang, X. J. (2007). Modeling of water sorption isotherm for corn starch. Journal Of Food Engineering, 80(2), 562-567. doi:10.1016/ j.jfoodeng.2006.04.063

Perry, E., \& Sibbett, G. (1998). Harvesting and storing your home orchards nut crop: almonds, walnuts, pecans, pistachios, and chestnuts. University of California, Division of Agriculture and Natural Resources Publication 8005. Retrieved from http:// anrcatalog.ucdavis.edu/pdf/8005.pdf

Prothon, F, \& Ahrné, L. M. (2004). Application of the Guggenheim, Anderson and De Boer model to correlate water activity and moisture content during osmotic dehydration of apples. Journal Of Food Engineering, 61(3), 467-470. doi:10.1016/S02608774(03)00119-5

Rizvi, S. S. H. (1986). Engineering properties of foods. In M. A. Rao \& S. S. H. Rizvi (Eds.), (Chap. Thermodynamic properties of food in dehydration. pp. 223-309). New York: Marcel Dekker.
Ruiz-Beviá, F, Fernández-Sempere, J, GómezSiurana, A, \& Torregrosa-Fuerte, E. (1999). Determination of sorption and diffusion properties of peeled almond nuts. Journal Of Food Engineering, 41(3-4), 209-214. doi:10 . 1016 / S0260 - 8774(99) 00092-8

Samaniego-Esguerra, C. M., Boag, I. F., \& Robertson, G. L. (1991). Comparison of regression methods for fitting the GAB model to the moisture isotherms of some dried fruit and vegetables. Journal of Food Engineering, 13(2), 115-133.

Shands, J., Lam, C., \& Labuza, T. P. (2010). Moisture sorption properties of commercially processed almonds. product development posters (146.06). In Institute of food technologies annual conference on food engineering division.

Sharma, P., Singh, R. R. B., Singh, A. K., Patel, A. A., \& Patil, G. R. (2009). Sorption isotherms and thermodynamics of water sorption of ready-to-use basundi mix. LWT-food Science And Technology, 42(1), 441-445. doi:10.1016/j.lwt.2008.04.010

Taitano, L. Z., Singh, R. P., Lee, J. H., \& Kong, F. B. (2011). Thermodynamic analysis of moisture adsorption isotherms of raw and blanched almonds. Journal of Food Process Engineering, ISSN: 1745-4530.

Taoukis, P. S., Labuza, T. P., \& Saguy, I. S. (1996). Food engineering practice. In K. J. Valentas, E. Rotstein \& R. P. Singh (Eds.), (Chap. Kinetics of food deterioration and shelf-life prediction. pp. 361-403). USA: CRC Press LLC.

Vazquez, G, Chenlo, F, \& Moreira, R. (2001). Modeling of desorption isotherms of chestnut: influence of temperature and evaluation of isosteric heats. Drying Technology, $19(6), 1189-1199$.

Wani, A. A., Sogi, D. S., Shivhare, U. S, Ahmed, I., \& Kaur, D. (2006). Moisture adsorption isotherms of watermelon seed and kernels. Drying Technology, 24(1), 99-104. doi:10. 1080/07373930500538881 